\title{
A Numerical Study on Mixed Convection of Water-Based Cuo Nanofluids in A Lid-Driven Square Enclosure: Effects of Viscosity Models
}

\author{
Kamil Kahveci ${ }^{1}$, Elif Büyük Öğüt ${ }^{2}$ \\ ${ }^{1}$ Mechanical Engineering Department, Trakya University, 22180 Edirne / Turkey \\ kamilk@trakya.edu.tr \\ ${ }^{2}$ Vocational School of Gebze, Kocaeli University, 41800 Hereke-Kocaeli / Turkey \\ elif.ogut@kocaeli.edu.tr
}

\begin{abstract}
Effects of various viscosity models on mixed convection of water-based CuO nanofluids in a lid-driven square enclosure with a constant heat flux heater were investigated numerically in this study. The computational results were obtained for the heater length of 0.50. The Grashof number was kept at a constant value of 104, and the Reynolds number was varied so that the Richardson number takes values in the range of 0.1 to 10 . Three different nanoparticle volume fraction were taken: $0 \%, 5 \%$ and $10 \%$. Results show that a little increase in circulation intensity for forced convection dominant flow regime and a decrease for natural convection dominant regime are seen when Pak and Cho viscosity model is used instead of Einstein viscosity model as a result of increase in viscosity. Results also show that the centre of circulation moves upward when the Pak and Cho viscosity model is used instead of Einstein viscosity model. Finally, Results show that the Einstein model gives the highest average Nusselt number while the Pak and Cho yields the lowest average Nusselt number. Differences in the average Nusselt numbers of Einstein, Brinkman and Batchlor models are in insignificant levels. Percentage difference in the average Nusselt numbers of Pak and Cho model and other models increases with an increase in solid volume fraction except for the Maiga model. Percentage difference between the average Nusselt numbers of Pak and Cho model and Maiga model shows a decrease with the solid volume fraction.
\end{abstract}

Keywords: Mixed convection, square enclosure, nanofluid, heat source, viscosity model.

\section{Introduction}

Low thermal conductivity of conventional heat transfer fluids such as water, oil and ethylene glycol is a primary limitation in enhancing the performance and the compactness of many devices in industrial applications. This limitation has been overcome by the introduction of nanofluids, which are the fluids with suspended solid particles of high thermal conductivity. The studies show that nanofluids have substantially larger thermal conductivities than those of conventional fluids [1]. The mechanisms behind this anomalous increase in thermal conductivity are: Brownian motion of the nanoparticles, molecular liquid layering at the nanoparticle interface, the nature of heat transfer, and nanoparticle clustering [2]. According to Keblinski et al. [2], Brownian motion has a negligible effect on thermal performance while liquid layering has a considerable effect. As there is no solid theory to estimate the thermal conductivity of nanofluids, models proposed for two-phase mixtures [3] are used. However, these models do not predict the thermal conductivity of nanofluid accurately. The experimental results show that the thermal conductivities of nanofluids are much higher than the predictions of these models. Yu and Choi [4] proposed an alternative thermal conductivity model for nanofluids by considering the effect of liquid layering around the nanoparticles. Yu and Choi [4] compared their model results with the existing experimental results in literature and found a good agreement. Yu and Choi [4] model is especially effective for the nanoparticles with a diameter less than $10 \mathrm{~nm}$. Yu Choi model has been used in this study for the prediction of thermal conductivity of nanofluids.

There are a number of studies in the literature on mixed convection heat transfer of nanofluids. Abu-Nada and Chamka [5] performed a numerical study on mixed convection flow in a lid-driven inclined square enclosure filled with a nanofluid. Their results show that average Nu number increases significantly with an increase in the inclination angle and particle volume fraction. Mahmoodi [6] performed a study on mixed convection flow and heat transfer in a lid-driven enclosure filled with a nanofluid. The results of this study show that the average Nusselt number for the tall enclosures is higher than those of the shallow enclosures. Elharfi et al. [7] studied mixed convection heat transfer for nanofluids in a lid-driven shallow 
rectangular enclosure uniformly heated and cooled from the vertical walls. They concluded that the addition of $\mathrm{Cu}-$ nanoparticles into the pure water leads to an enhancement or a degradation in heat transfer depending on the values of Re and Ri. Kefayati [8] studied mixed convection of non-Newtonian nanofluids in a lid-driven enclosure with a sinusoidal temperature profile and concluded that the fall of the power law index declines heat transfer and addition of nanoparticle augments heat transfer for studied parameters. Kahveci and Öğ̈̈t [9] performed a numerical investigation on mixed convection heat transfer and fluid flow in a lid-driven square enclosure heated with a constant heat flux heater. Their results show that the presence of nanoparticles in the base fluid causes a significant enhancement in heat transfer and heat transfer rate increases considerably with a decrease in the Richardson number and the length of the heater. Shahi et al. [10] conducted a numerical investigation of mixed convection flow through a copper-water nanofluid in a square cavity with inlet and outlet ports. The results indicate that increase in solid concentration leads to an increase in the average Nusselt number at the heat source surface and decrease in the average bulk temperature. Moumni and Sediki [11] worked on mixed convection of nanofluids in a ventilated square enclosure including two heat sources and found that adding nanoparticles to base fluid and increasing both $\mathrm{Re}$ and $\mathrm{Ri}$ number enhance heat transfer rate. Chamkha and Abu-Nada [12] performed a numerical investigation on steady laminar mixed convection flow in a square cavities filled with a nanofluid. Two viscosity models were used to approximate nanofluid viscosity: the Brinkman model and the Pak and Cho correlation. Their results show that the percent increase in the average Nusselt number using the Pak and Cho correlation is significantly higher than those corresponding to the Brinkman model for all values of nanoparticle volume fractions for a double-lid driven enclosure.

From the above literature, it can be concluded that there are not enough studies on the effects of different viscosity models on mixed convection of nanofluids in an enclosure. Therefore, this study aims to investigate the effects of viscosity models on mixed convection of nanofluids inside a square enclosure heated with a uniform heat flux.

\section{Analysis}

The geometry and the coordinate system used in the analysis are shown in Fig. 1. The top wall of the enclosure moves from left to the right with a constant velocity. A heater is attached to the bottom wall of the enclosure. Temperature of the moving wall is constant and the other walls are adiabatic. The nanofluid in the enclosure was assumed to be Newtonian, incompressible, and laminar and to have constant thermos-physical properties except for the density. The base fluid and nanoparticles were assumed to be in thermal equilibrium. Under these assumptions, dimensionless governing equations in vorticity-stream function formulation take the following form:

$$
\begin{gathered}
-\omega=\frac{\partial^{2} \psi}{\partial x^{2}}+\frac{\partial^{2} \psi}{\partial y^{2}} \\
u \frac{\partial \omega}{\partial x}+v \frac{\partial \omega}{\partial y}=\frac{\rho_{f}}{\rho_{n f, o}} \frac{1}{\operatorname{Re}} \frac{\mu_{e f f}}{\mu_{f}}\left(\frac{\partial^{2} \omega}{\partial x^{2}}+\frac{\partial^{2} \omega}{\partial y^{2}}\right)+\frac{(1-\phi) \rho_{f} \beta_{f}+\phi \rho_{s} \beta_{s}}{\beta_{f} \rho_{n f, o}} \frac{G r}{\operatorname{Re}^{2}}\left(\frac{\partial \theta}{\partial x}\right) \\
u \frac{\partial \theta}{\partial x}+v \frac{\partial \theta}{\partial y}=\frac{\alpha_{n f}}{\alpha_{f}} \frac{1}{\operatorname{Re} \operatorname{Pr}}\left(\frac{\partial^{2} \theta}{\partial x^{2}}+\frac{\partial^{2} \theta}{\partial y^{2}}\right)
\end{gathered}
$$

where $\rho, \mu, \beta, \alpha$, and $\phi$ is the density, viscosity, thermal expansion coefficient, thermal diffusivity, and nanoparticle volume fraction, respectively. $\mathrm{u}$ and $\mathrm{v}$ are the dimensionless velocity components in the $\mathrm{x}$ and $\mathrm{y}$ directions, respectively. $\theta$ is the dimensionless temperature. The subscripts nf, f, and s stand for the nanofluid, fluid, and solid, respectively. $\psi$ and $\omega$ are the dimensionless stream function and vorticity defined as:

$$
u=\frac{\partial \psi}{\partial y}, v=-\frac{\partial \psi}{\partial x} \quad, \quad \omega=\frac{\partial v}{\partial x}-\frac{\partial u}{\partial y}
$$

The Reynolds, Prandtl, and Grashof numbers are defined as: 


$$
\operatorname{Re}=\frac{U L \rho_{f, 0}}{\mu_{f}}, \operatorname{Pr}=\frac{\mu_{f}}{\rho_{f, 0} \alpha_{f}}, G r=\frac{\rho_{f, 0}^{2} g \beta_{f} L^{3} \Delta T}{\mu_{f}^{2}}
$$

where $\mathrm{L}$ is the length of the square enclosure, $\mathrm{g}$ is the gravitational acceleration, and $\mathrm{T}$ is the temperature.

The dimensionless variables used in the nondimensionalization of the governing equations are:

$$
x=\frac{x^{*}}{L}, \quad y=\frac{y^{*}}{L}, \quad u=\frac{u^{*}}{U}, \quad v=\frac{v^{*}}{U} \quad, \quad p=\frac{p^{*}}{\rho_{f, 0} U^{2}} \quad, \quad \theta=\frac{T^{*}-T_{C}}{\Delta T} \quad \Delta T=\frac{q^{\prime \prime} L}{k_{f}}
$$

where $\mathrm{U}$ is the velocity of the cold top wall, $\mathrm{k}$ is the thermal conductivity, and q" is the heat flux. The subscript $\mathrm{c}$ stands for the cold wall.

Governing equations are subjected to the following boundary conditions:

$$
\begin{gathered}
\theta=0, u=1, v=0 \text { at } y=1 \\
\partial \theta / \partial y=0 \text { at } y=0 \text { and } 0 \leq x<(\mathrm{a}-\varepsilon / 2) \\
\partial \theta / \partial y=-k_{f} / k_{n f} \text { at } y=0 \text { and }(\mathrm{a}-\varepsilon / 2) \leq x \leq(\mathrm{a}+\varepsilon / 2) \\
\partial \theta / \partial y=0 \text { at } y=0 \text { and }(\mathrm{a}+\varepsilon / 2)<x \leq 1, \\
u=v=0 \text { at } \mathrm{y}=0
\end{gathered}
$$

where $\mathrm{a}^{*}$ is the distance of the heater midpoint from the vertical wall. $\varepsilon$ is the dimensionless length of the heater defined as $\varepsilon=\mathrm{w} / \mathrm{L}$ and $\mathrm{a}$ is the dimensionless distance of the heater midpoint defined as $\mathrm{a}=\mathrm{a}^{*} / \mathrm{L}$.

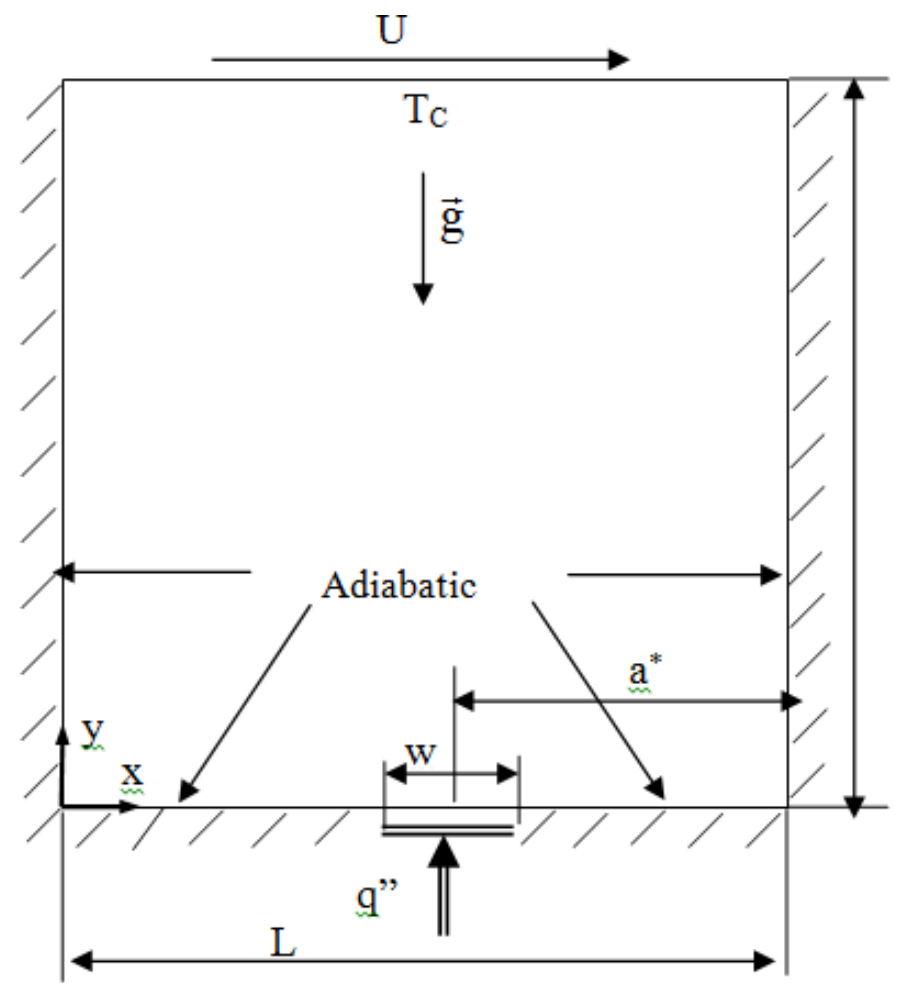

Fig. 1: Geometry and the coordinate system.

Nanofluid viscosity is one of the most important factors in convective heat transfer because it has an important effect on flow and heat transfer. Several viscosity formulations based on nanoparticle volume fraction seen in Table 1 were used in this study to reveal the effect of these models on the flow and heat transfer. 
Table 1: Viscosity models.

\begin{tabular}{|l|l|}
\hline Model & Effective viscosity \\
\hline Einstein & $\mu_{\text {eff }}=\mu_{f}(1+2.5 \phi)$ \\
\hline Brinkman & $\mu_{\text {eff }}=\mu_{f} /(1-\phi)^{2.5}$ \\
\hline Batchlor & $\mu_{\text {eff }}=\mu_{f}\left(1+2.5 \phi+6.5 \phi^{2}\right)$ \\
\hline Maiga & $\mu_{\text {eff }}=\mu_{f}\left(1+7.3 \phi+123 \phi^{2}\right)$ \\
\hline Pak and Cho & $\mu_{\text {eff }}=\mu_{f}\left(1+39.11 \phi+533.9 \phi^{2}\right)$ \\
\hline
\end{tabular}

The thermal conductivity model proposed by Yu and Choi [13] was used in this study to predict the nanofluid thermal conductivity.

$$
\frac{k_{e f f}}{k_{f}}=\frac{k_{s}+2 k_{f}+2\left(k_{s}-k_{f}\right)(1+\eta)^{3} \phi}{k_{s}+2 k_{f}-\left(k_{s}-k_{f}\right)(1+\eta)^{3} \phi}
$$

where $\eta$ is the ratio of the liquid layering thickness to the original particle radius.

The other thermos-physical properties of nanolfuid are defined $₫$ :

$$
\begin{gathered}
\rho_{n f, o}=(1-\phi) \rho_{f, o}+\phi \rho_{s, o} \\
\left(\rho c_{p}\right)_{n f}=(1-\phi) \rho_{f} c_{p_{f}}+\phi \rho_{s} c_{p s} \\
(\rho \beta)_{n f}=(1-\phi) \rho_{f} \beta_{f}+\phi \rho_{s} \beta_{s}
\end{gathered}
$$

where $c_{p}$ is the specific heat.

The local heat transfer coefficient is defined as:

$$
h_{x}=\frac{q^{\prime \prime}}{\left(T_{s}(x)-T_{c}\right)}
$$

where $\mathrm{h}_{\mathrm{x}}$ is the local heat transfer coefficient. The local and average Nusselt numbers for the heated wall can be defined as follows:

$$
\begin{gathered}
N u=\frac{h_{x} L}{k_{f}}=\frac{1}{\theta_{s}(x)} \\
N u_{a}=\frac{1}{\varepsilon} \int_{a-\varepsilon / 2}^{a+\varepsilon / 2} \frac{1}{\theta_{s}(x)} d x
\end{gathered}
$$

where $\theta_{\mathrm{s}}(\mathrm{x})$ is the dimensionless local temperature of the heated wall.

\section{Results and Discussion}

The solutions of governing equations were obtained by Comsol Multiphysics finite element modelling and simulation software. The thermo-physical properties of the base fluid and solid particles $(\mathrm{CuO})$ used in this study are shown in Table 2. The Grashof number was kept constant with a value of $10^{4}$, and the Reynolds number was varied such that the Richardson number gets values in the range 0.1-10. The Richardson number is defined as $\mathrm{Ri}=\mathrm{Gr} / \mathrm{Re}^{2}$ and represents the relative 
importance of buoyancy forces with respect to the shear forces. Three different nanoparticle volume fractions were considered in this study: $0 \%, 5 \%$, and $10 \%$ and $\eta$, the ratio of the liquid layering to the original particle radius, was taken as 0.1 .

Table 2: Thermo-physical properties of the base fluid and nanoparticle.

\begin{tabular}{|l|l|l|}
\hline Property & Water & $\mathrm{CuO}$ \\
\hline$\rho\left(\mathrm{kg} / \mathrm{m}^{3}\right)$ & 997.1 & 6500 \\
\hline$c_{\mathrm{p}}(\mathrm{j} / \mathrm{kg} \mathrm{K})$ & 4179 & 535.6 \\
\hline $\mathrm{k}(\mathrm{W} / \mathrm{m} \mathrm{K})$ & 0.613 & 20 \\
\hline$\alpha \times 10^{7}\left(\mathrm{~m}^{2} / \mathrm{s}\right)$ & & \\
\hline$\beta\left(\mathrm{K}^{-1}\right)$ & 1.47 & 57.45 \\
& & 0.000051 \\
\hline
\end{tabular}

Streamlines and isotherms inside the enclosure are shown in Figure 2 for the Einstein viscosity model. As it can be observed from Figure 2, a clockwise rotating circulation cell forms the flow field for all values of the Richardson number by the effect of lid moving from left to right. Circulation centre is in the upper part of the enclosure as a result of the higher shear forces in the upper part of enclosure. With an increase in the Richardson number, circulation centre moves upward because of the increase in the buoyancy forces. Variation in the circulation intensity with an increase in the nanoparticle volume fraction seems to be insignificant because of the counter-effects of the increased thermal conductivity and viscosity. An increase in the solid particle volume fraction increases the thermal conductivity and viscosity. An increase in the thermal conductivity has a positive effect on the circulation intensity. On the other hand, an increase in the viscosity has a negative effect on the circulation intensity. As a result, change in circulation intensity remains in insignificant levels. Because of the clockwise rotating flow, isotherms along the heater are more compressed on the right side of the enclosure, and they become more separated as the fluid particles are heated during their journey towards left. Temperature also takes higher values toward the left side wall of the enclosure due to the clockwise rotating circulation. With an increase in the solid volume fraction, the slope of isotherms inside the enclosure decreases because of the increasing energy transport from the hot wall to the nanofluid due to the higher thermal conductivity.

The streamlines and isotherms inside the enclosure are shown in Figure 2 for the Pak and Cho viscosity model. Pak and Cho viscosity model produces highest viscosity predictions for nanofluid viscosity. Therefore, an increase in circulation intensity for forced convection dominant flow regime and a decrease for natural convection dominant regime are seen when this model is used. The circulation centre moves upward as a result of increase in the shear forces with the increase in the viscosity. As a result of circulation centre closer to the top wall for low values of Richardson number and low circulation intensity for the high values of the Richardson number, isotherms along the heater are more separated in the vertical direction. The variation of the average Nusselt number is shown in Table 3 for the viscosity models considered in this study. It can be concluded from Table 3 that the Einstein model gives the highest average Nusselt number and the Pak and Cho yields the lowest average Nusselt number. On the other hand, differences between the results of Einstein, Brinkman and Batchlor models are in insignificant levels. Percentage difference in the average Nusselt numbers of the Pak and Cho model and other models increases with an increase in the solid volume fraction except for the Maiga model. Percentage difference in the average Nusselt numbers of the Maiga model and Pak and Cho model shows a decrease with the solid volume fraction. 


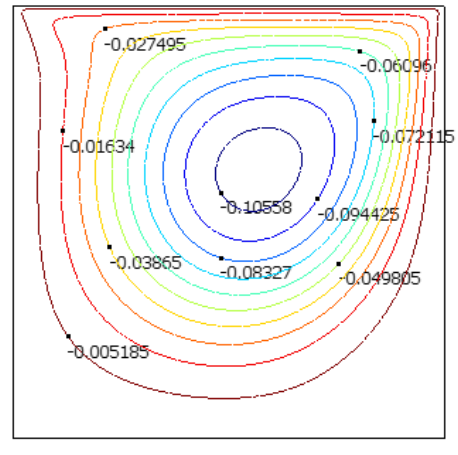

$\phi=0.0$

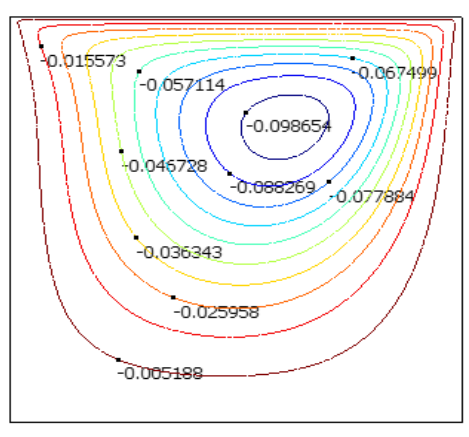

$\phi=0.0$

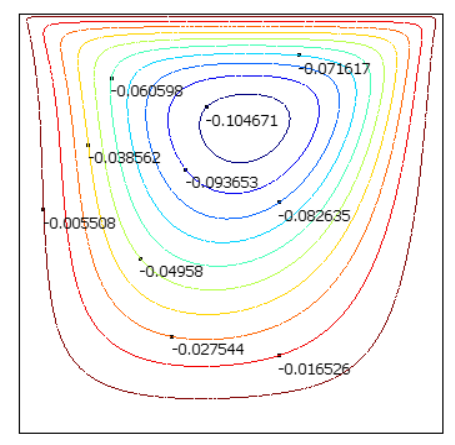

$\phi=0.0$

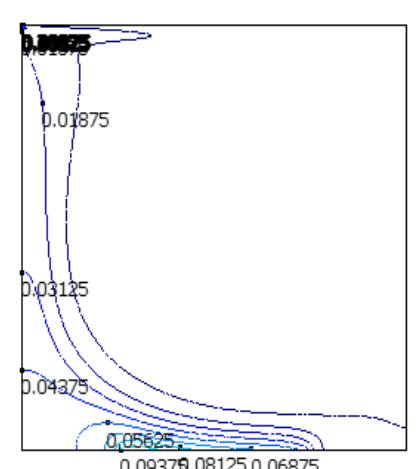

0.09379 .081250 .06875
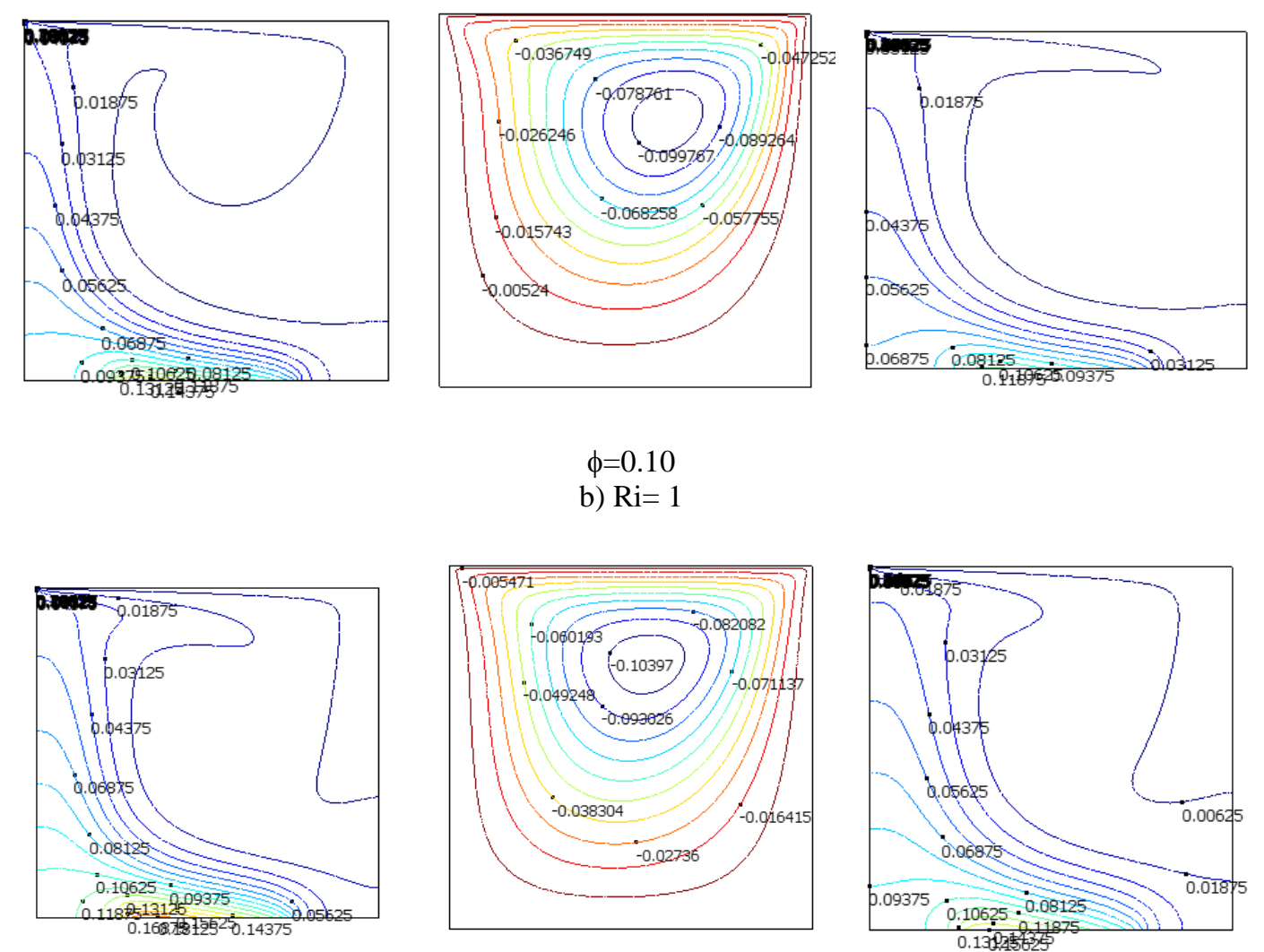

$\phi=0.10$

c) $\mathrm{Ri}=10$ $\phi=0.10$

b) $\mathrm{Ri}=1$
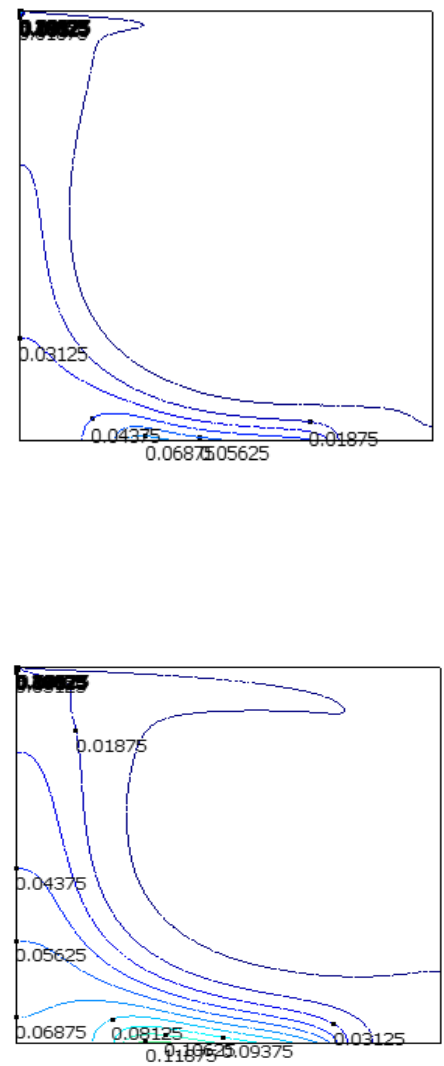

0.9189695 .09375

$\phi=0.10$

a) $\mathrm{Ri}=0.1$

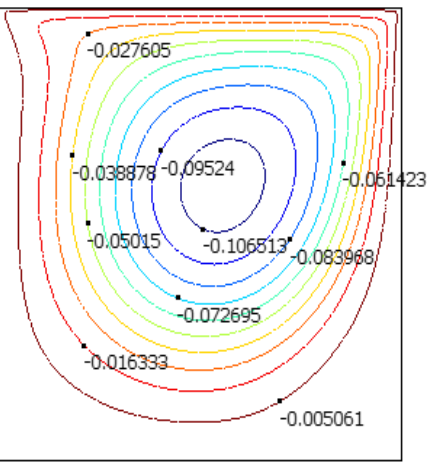

13024526

Fig. 3: Streamlines and isotherms for the Einstein model for a) $\mathrm{Ri}=0.1, \mathrm{~b}) \mathrm{Ri}=1$, c) $\mathrm{Ri}=10$. 


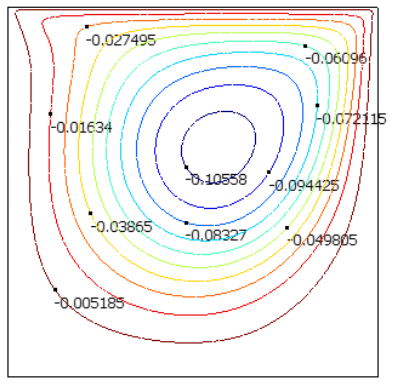

$\phi=0.0$

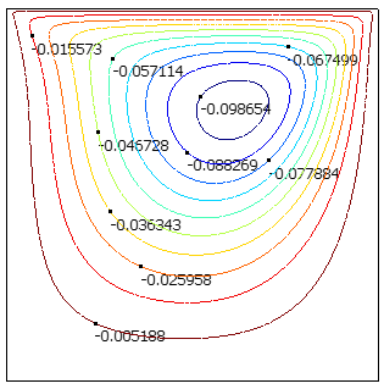

$\phi=0.0$

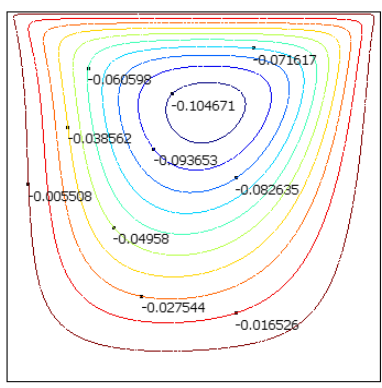

$\phi=0.0$

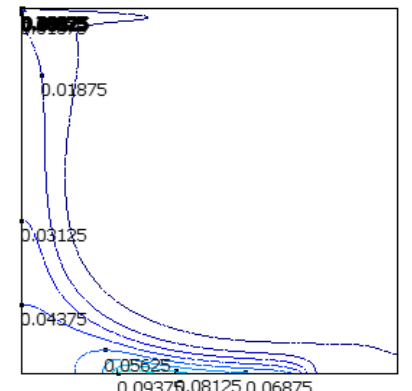

0.09379 .081250 .06875

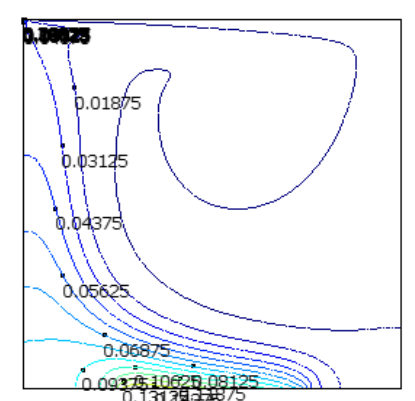

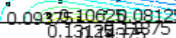

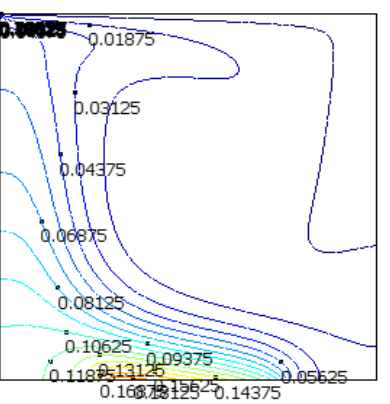

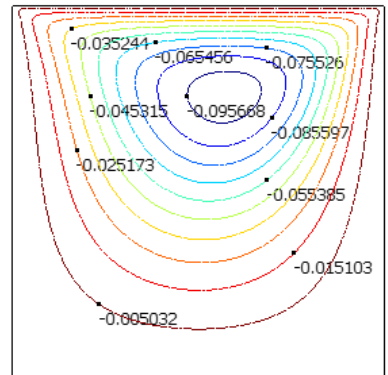

$\phi=0.10$

a) $\mathrm{Ri}=0.1$

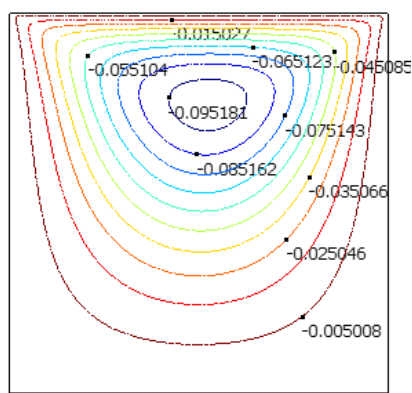

$\phi=0.10$

b) $\mathrm{Ri}=1$

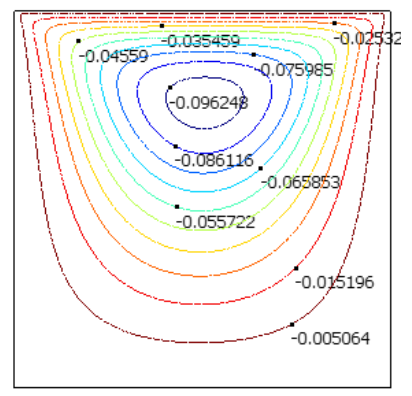

$\phi=0.10$

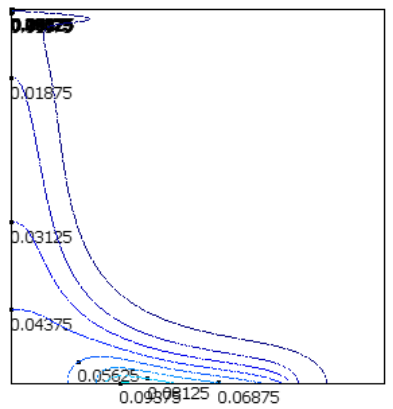

0.0939891250 .06875
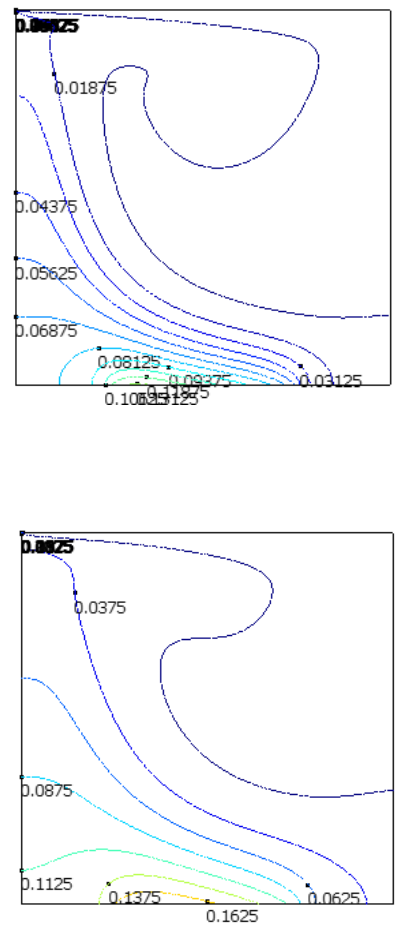

c) $\mathrm{Ri}=10$

Fig. 4: Streamlines and isotherms for the Pak and Cho model for a) $\mathrm{Ri}=0.1, \mathrm{~b}) \mathrm{Ri}=1$, c) $\mathrm{Ri}=10$.

Table 3: Variation of the average Nusselt number for different viscosity models.

\begin{tabular}{|c|c|c|c|c|c|c|}
\hline \multirow{2}{*}{$\mathrm{Ri}$} & $\phi$ & $\begin{array}{c}\text { M1 } \\
\text { Einstein }\end{array}$ & $\begin{array}{c}\text { M2 } \\
\text { Brinkman }\end{array}$ & $\begin{array}{c}\text { M3 } \\
\text { Batchlor }\end{array}$ & $\begin{array}{c}\text { M4 } \\
\text { Maiga }\end{array}$ & $\begin{array}{c}\text { M5 } \\
\text { Pak and Cho }\end{array}$ \\
\hline \multirow{3}{*}{00.1} & 0.00 & 13.42 & 13.42 & 13.42 & 13.42 & 13.42 \\
\cline { 2 - 7 } & 0.05 & 15.45 & 15.41 & 15.40 & 14.36 & 13.21 \\
\cline { 2 - 7 } & 0.10 & 17.59 & 17.44 & 17.39 & 15.25 & 14.50 \\
\hline \multirow{3}{*}{11} & 0.00 & 8.42 & 8.42 & 8.42 & 8.42 & 8.42 \\
\cline { 2 - 7 } & 0.05 & 9.37 & 9.37 & 9.36 & 9.12 & 8.82 \\
\cline { 2 - 7 } & 0.10 & 10.41 & 10.37 & 10.36 & 9.89 & 9.66 \\
\hline \multirow{3}{*}{110} & 0.00 & 6.66 & 6.66 & 6.66 & 6.66 & 6.66 \\
\cline { 2 - 7 } & 0.05 & 7.25 & 7.24 & 7.24 & 6.91 & 6.28 \\
\cline { 2 - 7 } & 0.10 & 7.87 & 7.83 & 7.82 & 7.14 & 6.56 \\
\hline
\end{tabular}




\section{Conclusion}

In this study, effects of various viscosity models on mixed convection heat transfer and fluid flow in a lid driven square enclosure with a constant heat flux heater has been investigated numerically. The concluding remarks are as follows: An increase for forced convection dominant flow regime and a decrease for natural convection dominant regime are seen in the circulation intensity when the Pak and Cho viscosity model is used instead of the Einstein viscosity model. Circulation centre gets closer to the top wall when the Pak and Cho viscosity model is used instead of the Einstein model. The Einstein model gives the highest average Nusselt number while the Pak and Cho yields the lowest average Nusselt number. The circulation centre moves upward when the Pak and Cho viscosity model is used instead of Einstein viscosity model. Differences in the average Nusselt numbers of the Einstein, Brinkman and Batchlor models are in insignificant levels. Percentage difference in the average Nusselt numbers of the Pak and Cho model and other models increases with an increase in solid volume fraction except for the Maiga model. Percentage difference between the average Nusselt numbers of the Maiga model and Pak and Cho model shows a decrease with the solid volume fraction.

\section{References}

[1] J. A. Eastman, S. U. S. Choi, S. Li, W. Yu, and L. J. Thompson, "Anomalously increased effective thermal conductivities of Ethylene glycol-based nanofluids containing copper nanoparticles," Applied Physics Letters, vol. 78, pp. 718-720, 2001.

[2] P. Keblinski, S. R. Phillpot, S. U. S. Choi, and J. A. Eastman, "Mechanisms of heat flow in suspensions of nano-sized particles (nanofluids)," International Journal of Heat and Mass Transfer, vol. 45, pp. 855-863, 2002.

[3] R. L. Hamilton and O. K. Crosser, "Thermal conductivity of heterogeneous two-component systems," I \& EC Fundamentals, vol. 1, pp. 182-191, 1962.

[4] W. Yu and S. U. S. Choi, "The role of interfacial layer in the enhanced thermal conductivity of nanofluids: a renovated Maxwell model," Journal of Nanoparticles Research, vol. 5, pp. 167-171, 2003.

[5] E. Abu-Nada and A. J. Chamkha, "Mixed convection flow in a lid-driven inclined square enclosure filled with a nanofluid," European Journal of Mechanics B/Fluids, vol. 29, pp. 472-482, 2010.

[6] M. Mahmoodi, "Mixed convection inside nanofluid filled rectangular enclosures with moving bottom wall," Thermal Science, vol. 15, no. 3, pp. 889-903, 2011.

[7] H. Elharfi, M. Naimi, M. Lamsaadi, A. Raji, and M. Hasnaoui, "Mixed convection heat transfer for nanofluids in a liddriven shallow rectangular cavity uniformly heated and cooled from the vertical sides: the cooperative case," ISRN Thermodynamics, vol. 2012, pp. 1-16, 2012.

[8] G. H. R. Kefayati, "Mixed convection of non-Newtonian nanofluids flows in a lid-driven enclosure with sinusoidal temperature profile using FDLBM," Powder Technology, vol. 266, pp. 268-281, 2014.

[9] K. Kahveci and E.B. Öğ̈̈t, "Mixed convection of water-based nanofluids in a lid-driven square enclosure with a heat source," Heat Transfer Research, vol. 42, no. 8, pp. 711-735, 2011.

[10] M. Shahi, A. H. Mahmoudi, and F. Talebi, "Numerical study of mixed convective cooling in a square cavity ventilated and partially heated from the below utilizing nanofluid," International Communications in Heat and Mass Transfer, vol. 37, no.2, pp. 201-213, 2010.

[11] H. Moumni and E. Sediki, "Enhanced mixed convection and heat transfer by nanofluid in ventilated square enclosure including two heat sources," Computational Thermal Sciences: An Internatinal Journal, vol. 7, no. 1, pp. 15-34, 2015.

[12] A. J. Chamkhaa and E. Abu-Nada, "Mixed convection flow in single- and double-lid driven square cavities filled with water- $\mathrm{Al}_{2} \mathrm{O}_{3}$ nanofluid: effect of viscosity models," European Journal of Mechanics B/Fluids, vol. 36, pp. 82-96, 2012.

[13] W. Yu and S. U. S. Choi, "The role of interfacial layer in the enhanced thermal conductivity of nanofluids: a renovated Maxwell model," Journal of Nanoparticle Research, vol. 5, pp. 167-171, 2003. 